\title{
Laboreal
}

Volume $1 \mathrm{~N}^{\circ} 1$ | 2005

Varia

\section{As dramáticas do uso de si de jovens mães trabalhadoras : cartografias do trabalho em insuspeitáveis territórios}

Las dramáticas del uso de si de jóvenes madres trabajadoras : cartografías del trabajo en insospechables territorios

Les dramatiques de l'usage de soi chez de jeunes mères qui travaillent:

cartographies du travail en des territoires insoupçonnés

Self use dramatics of young working mothers : cartographies of work in unsuspected territories

\section{Suyanna Barker}

\section{(2) OpenEdition}

\section{Journals}

\section{Edição electrónica}

URL: http://journals.openedition.org/laboreal/14098

DOI: $10.4000 /$ laboreal. 14098

ISSN: 1646-5237

\section{Editora}

Universidade do Porto

\section{Refêrencia eletrónica}

Suyanna Barker, «As dramáticas do uso de si de jovens mães trabalhadoras : cartografias do trabalho em insuspeitáveis territórios », Laboreal [Online], Volume 1 N¹ | 2005, posto online no dia 01 dezembro 2005, consultado o 24 setembro 2020. URL : http://journals.openedition.org/laboreal/ 14098 ; DOI : https://doi.org/10.4000/laboreal.14098

Este documento foi criado de forma automática no dia 24 setembro 2020.

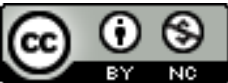

Laboreal está licenciado com uma Licença Creative Commons - Atribuição-NãoComercial 4.0 Internacional. 


\section{As dramáticas do uso de si de jovens mães trabalhadoras : cartografias do trabalho em insuspeitáveis territórios}

Las dramáticas del uso de si de jóvenes madres trabajadoras : cartografías del trabajo en insospechables territorios

Les dramatiques de l'usage de soi chez de jeunes mères qui travaillent :

cartographies du travail en des territoires insoupçonnés

Self use dramatics of young working mothers : cartographies of work in unsuspected territories

\section{Suyanna Barker}

\section{REFERÊNCIA}

Linhales Barker, S. (2005). As Dramáticas do uso de si de jovens mães trabalhadoras : cartografias do trabalho em insuspeitáveis territórios. Tese de Doutoramento. Rio de Janeiro : Escola Nacional de Saúde Pública Sergio Arouca, Fundação Oswaldo Cruz.

\section{NOTA DO EDITOR}

Manuscrito recebido em : Setembro/2005

Aceite após peritagem em : Setembro/2005

1 Tese de doutorado defendida na Escola Nacional de Saúde Pública Sergio Arouca ENSP da Fundação Oswaldo Cruz na cidade do Rio de Janeiro, Brasil em junho de 2005. Contou com a orientação da Pesquisadora Jussara Cruz de Brito da ENSP e co-orientação de 
Maria Elizabeth Barros de Barros, Professora da Universidade Federal do Espírito Santo e teve como objetivo principal transformar para compreender o trabalho de jovens mães trabalhadoras, moradoras de uma favela na cidade do Rio de Janeiro.

2 A necessidade de transformar para compreender se deveu ao fato dessas mulheres jovens, com histórias de gravidez e trabalho na adolescência, não serem reconhecidas, nem socialmente, nem por elas mesmas como trabalhadoras. Em parte isso ocorre devido à tenra idade com a qual ingressam no mercado informal de trabalho. Existem em todo o Brasil cinco milhões e meio de crianças e adolescentes, entre cinco e dezessete anos, economicamente ativos, estando a maior concentração desses trabalhadores entre os adolescentes, que apesar de terem idade legal para o trabalho, estão em sua maioria empregados no mercado informal, e sem garantias previdenciárias e trabalhistas. Além disso, as estatísticas apontam uma inclusão maior de mulheres em geral no mercado de trabalho, existindo, porém, um gueto no serviço doméstico para as mulheres jovens, sem qualificação formal e que já tenham pelo menos um filho. Este quadro reflete o fenômeno da feminização da pobreza no Brasil que faz com que espaços populares denominados favelas sejam habitados por famílias chefiadas por mulheres, que se empregam antes de completarem uma formação profissional e conseqüentemente se transformam em mão de obra barata e flexível capaz de suprir necessidades exploratórias do capitalismo tardio. Esta conjuntura faz com que o trabalho destas mulheres se torne invisível e pouco valorizado. A falta de reconhecimento e de espaço para compreender a atividade de trabalho destas jovens produz um grupo de trabalhadoras que desconhece suas próprias habilidades e astúcias para lidar com a pobreza e criar seus filhos com dignidade. Buscar compreender as atividades de trabalho destas jovens requereu a construção de uma abordagem de pesquisa que transformasse o já conhecido sobre estas mulheres e instituísse novas compreensões sobre suas atividades de trabalho.

3 Este estudo partiu de uma revisão bibliográfica sobre a situação de trabalho de mulheres, crianças e jovens no Brasil e a interpelação da reprodução neste fenômeno. A seguir, a partir dos conceitos de modos de subjetivação (Foucault, 1977) e produção de subjetividade (Deleuze \& Guattari, 1987), formou-se um marco teórico para a compreensão da dimensão subjetiva deste acontecimento. Os pressupostos teóricos da ergonomia da atividade situada (Teiger,1998), da Psicodinâmica do trabalho (Dejours, 1999), assim como, os conceitos de normas antecedentes, corpo-si e dramáticas do uso de si da Ergologia (Durrive \& Schwartz, 2003) foram o manancial para o entendimento da dimensão subjetiva atravessada pela atividade de trabalho. Para a coleta dos dados empíricos foram fundamentais os pressupostos da Clínica da Atividade desenvolvida por Yves Clot (Clot, 2001), em especial no uso que este faz da técnica de Instrução ao sósia forjada por Oddone e colaboradores (Clot, 1999). Também, das análises realizadas pela Clínica da Atividade, usou-se o conceito de atividade impedida como fonte de sofrimento psíquico.

4 A seguir, construiu-se uma metodologia de pesquisa-intervenção baseada nos pressupostos da Análise Institucional francesa, na forma como esta foi apropriada no Brasil (Rocha \& Aguiar, 2003). Segundo a Análise Institucional, uma pesquisaintervenção busca produzir um diálogo entre teoria e prática onde não há a anterioridade de uma em comparação com a outra. Como metodologia básica colocouse em análise o sentido instituído sobre o trabalho e a maternagem e, ativamente, mapearam-se os movimentos, as diferenciações e as possibilidades de outros sentidos. 
Também foram escolhidas para este estudo técnicas de investigação utilizadas nas ciências humanas e sociais, em especial aquelas em que os sujeitos da pesquisa atuam ativamente no processo de produção de conhecimento (Becker, 1993 ; Certeau, 1994). Para a execução da pesquisa foram realizados grupos de discussão semanais, por um período de seis meses, junto a um Centro Comunitário em uma das favelas da cidade do Rio de Janeiro. Para participar destes encontros foram convidadas mulheres jovens com história de gravidez e trabalho na adolescência e a cada encontro o grupo produziu material gráfico e discursivo que foi registrado e usado posteriormente na análise dos dados. A pesquisa contou com quatro fases distintas de execução, desde a negociação com o centro comunitário até as entrevistas individuais realizadas ao final do processo. Além desta tese, estes encontros também produziram uma cartilha, elaborada pelas jovens e endereçada a outras mulheres que estejam passando pelas mesmas experiências de vida e trabalho. Este material sintetiza as discussões efetuadas no grupo durante os meses de pesquisa-intervenção.

5 A ação de transformar para compreender o trabalho, empreendida pelo caminho metodológico acima descrito efetuou uma ampliação no entendimento sobre as atividades realizadas pelas jovens mães, assim como propiciou que estas se percebessem como sujeitos com competência para falar de suas atividades de trabalho. Desse modo foi possível agregar um bom número de histórias, contadas pelas jovens e discutidas no grupo de pesquisa, onde foram se explicitando os debates de valores efetuados no curso das diversas atividades que realizam em suas vidas, ou seja, suas dramáticas do uso de si. A composição que foi realizada ao se dispor o contexto do trabalho precoce feminino e as ferramentas conceituais escolhidas para dialogar com as histórias singulares das jovens mães trabalhadoras produziram seis pistas-resultados de suma importância para as análises das questões de saúde e trabalho de jovens trabalhadoras, sejam elas :

6 (1) Constatou-se que, entre mulheres jovens, moradoras de espaços populares e com história de gravidez na adolescência, a discussão da composição saúde e trabalho não aparece de forma espontânea, necessitando uma metodologia de intervenção que produza linguagem sobre o trabalho que elas executam e seus efeitos sobre a saúde. Ao final da intervenção, conseguiuse notar atividades de trabalho onde elas pareciam não existir e, assim, cartografou-se o trabalho em insuspeitáveis territórios. Para isso, foi necessário tanto ampliar a noção de trabalho e perceber seu caráter enigmático quanto considerar que existem modos sexuados de viver e trabalhar.

7 (2) Observou-se que a constituição do grupo "A Favor Delas", que aconteceu durante o processo da pesquisa-intervenção, propiciou o desvendamento do caráter coletivo do trabalho das jovens mães e a importância dessa coletividade para o enfrentamento dos mais diversos desafios experimentados por elas. Começou-se a cartografar, então, as Entidades Coletivas Relativamente Pertinentes (Durrive \& Schwartz, 2003) em meios não tradicionalmente pensados como ambientes de trabalho. Ao ampliar-se o conceito de ECRP para esses novos territórios, percebeu-se que o trabalho precoce feminino acontece em rede com outras mulheres, no âmbito doméstico e produtivo, desde muito cedo na vida das meninas de classe popular, mas não se configura como um coletivo único e constante, mas sim como uma lógica de trabalho, sucessivamente plural, mas sempre relativamente pertinente.

8 (3) Verificou-se que o real da atividade de trabalho de mulheres jovens, chefes de família, impõe uma jornada de trabalho ampliada que lhes dificulta o acesso à educação 
formal e a cursos de qualificação profissional. Ao mesmo tempo, propicia o aprendizado de uma série de habilidades e um agir em competência (Durrive \& Schwartz, 2003) que ainda não gozam de reconhecimento social, embora sejam extremamente úteis para o atual mundo de trabalho. O reconhecimento desse patrimônio acumulado informalmente deve estar na base de qualquer iniciativa que busque oportunizar trabalho digno para as classes populares.

9 (4) Identificou-se a premência do trabalho imaterial (manipulação do afeto nas atividades de cuidar e atender as pessoas) para as mulheres pobres tanto nas atividades de reprodução social como nas atividades ligadas ao trabalho desqualificado, típico da trabalhadora jovem das camadas populares. Abriu-se, assim, a possibilidade de ampliar a noção de trabalho imaterial para além daquele relacionado apenas às atividades intelectualizadas. Essa ampliação pode ser o marco conceitual para se entender um trabalho tão difícil de mensurar, ou seja, cuidar das pessoas e fazer a reprodução social.

(5) Notou-se que a reprodução tem um valor singular para jovens moradoras de espaços populares e remete para a possibilidade de planejar e investir no futuro. Diante da certeza de que o adiamento da reprodução não implicará necessariamente mobilidade social, mulheres jovens fazem uso da maternidade como forma de conquista de autonomia e direcionamento da vida adulta. Neste sentido, o ritual reprodutivo muito se assemelha ao processo de reconhecimento social forjado pela possibilidade de trabalho produtivo digno e executado como profissão.

11 (6) Observou-se que os processos de impedimento das atividades de trabalho, causados pela falta de reconhecimento social das habilidades aprendidas no âmbito doméstico, são fonte de sofrimento, pois estão associados a uma margem de manobra restrita que dificulta os processos de re-singularização das experiências de trabalho. $O$ sofrimento advém mais daquilo que não pode ser desenvolvido do que das dificuldades inerentes a uma atividade de trabalho.

\section{BIBLIOGRAFIA}

Becker, H.S. (1993). Método de pesquisa em ciências sociais. São Paulo : Hucitec.

Certeau, M. (1994). A Invenção do Cotidiano. Petrópolis : Editora Vozes.

Clot, Y. (1999). I. Oddone : les instruments de l'action. Territoires du travail, 3.

Clot, Y. (2001). Clinique du travail, clinique du réel. Le journal des psychologues, 185, 48-51.

Dejours, C. (1999). A Banalização da Injustiça Social. Rio de Janeiro : Editora FGV.

Deleuze, G. \& Guattari, F. (1987). A Thousand Plateaus : capitalism \& schizophrenia. Minneapolis : University of Minnesota Press.

Durrive, L. \& Schwartz, Y. (2003). Travail et Ergologie : entretiens sur l'activité humaine. Toulouse : Octarès Éditions.

Foucault, M. (1977). Discipline and punish : the birth of the prison. New York : Vintage Books. 
Rocha. M.L. \& Aguiar, K.F. (2003). Pesquisa-intervenção e a Produção de Novas Análises. Psicologia Ciência e Profissão, Brasília - CFP, 2003, 4, 24-33.

Teiger, C. (1998). Las representaciones funcionales en el trabajo. Ergonomía : conceptos y métodos. Madri : Editorial Complutense.

\section{AUTOR}

\section{SUYANNA BARKER}

Universidade do Estado do Rio de Janeiro, Brasil, Rua Aiurú, \# 73/201, Humaitá, Rio de Janeiro, RJ, CEP : 22261-110, Brasil

suyanna@uerj.br 